\title{
Biografismo e retórica: a escrita biográfica no ensino superior
}

\author{
Éber José dos Santos ${ }^{1}$ \\ Tiago Ramos e Mattos ${ }^{2}$
}

$\mathbf{B}_{\text {iografia é a apreciação da vida, e nossas vidas não são estáticas, tam- }}$ B pouco o espaço biográfico. Trata-se nesse espaço de um eu-para-si que não é constitutivo da forma, mas da relação que cada um de nós tem com os outros, contemporâneos que participam conosco do nosso dia a dia e integram um grupo de pessoas que vivem o hoje. O meu hoje é seu hoje, do qual todos nós participamos. Na biografia de cada um de nós, busca-se a constituição de uma identidade e o encontro da identificação com valores sociais.

A partir desse contexto e com enfoque na escola, levantamos o seguinte questionamento: por meio do princípio de alteridade (interação entre o eu e o outro), quais os lugares retóricos ${ }^{3}$ que o aluno, orador-autor, utiliza para imprimir veracidade, convencimento e persuasão, quando escreve um texto biográfico?

Desse modo, este capítulo tem como objetivo saber, achar e avaliar os argumentos encontrados na escrita do gênero biografia que justifiquem a busca pela veridicção. Para cumprir essa tarefa, buscamos analisar um

\footnotetext{
$1 \quad$ Mestre em Língua Portuguesa pela PUC-SP; Membro do Grupo ERA.

2 Doutorando em Língua Portuguesa pela PUC-SP; Mestre em Língua Portuguesa pela PUC-SP; Membro do Grupo ERA e LEDIMI (Leitura Discurso e Mídia); Bolsista CAPES.

3 "Os lugares são grandes armazéns de argumentos, utilizados para estabelecer acordo com o auditório” (FERREIRA, 2010, p. 69).
} 
texto biográfico produzido por um aluno do Ensino Superior Tecnológico que escreveu sobre a vida do amigo. Pela análise sóciorretórica ${ }^{4}$ realizada, foi possível identificar que as preferências do aluno-biógrafo quanto a argumentos são: enaltecer as qualidades do aluno-biografado e de seu valor como pessoa.

\section{Escrita e retórica}

Cotidianamente, e de maneira insistente, somos requisitados pela escrita, seja nas mídias digitais - nos anúncios incômodos que invadem nossas retinas quando tentamos ver um vídeo no YouTube - no Whatsapp, na internet de um modo geral, assim como no trabalho, nas entrevistas de emprego e em formulários e relatórios intermináveis. Na escola, de um modo geral, aparece em gêneros discursivos bastante conhecidos por todos nós: a poesia, o conto, a crônica, o romance etc.

Somos convidados à leitura o tempo todo pela escrita em outdoors, placas de trânsito, anúncios, bilhetes, e-mails e propagandas das mais variadas, portanto, nesse contexto, nada faz mais sentido do que a afirmação de que a escrita é uma prática social. Se perguntássemos aos alunos o que pensam sobre escrever, a resposta seria: "para escrevermos - e fazê-lo bem -, é preciso conhecer as regras gramaticais da língua e ter um bom vocabulário", afirmam Kock \& Elias (2009, p. 32). Bazerman (2015), ao tratar de contexto, escrita e retórica, chama-nos a atenção para isso:

A escrita nos chega em folhas de papel ou telas digitais que se parecem muito umas com as outras, obscurecendo de onde a mensagem pode ter vindo, qual seu destino e que objetivo se destinava a realizar e em que circunstâncias. Se os textos viajam pelo tempo e pelo espaço, onde está seu contexto? Eles mesmos criam seus próprios contextos, aqueles a quem então falam? A menos que tenhamos meios de escrever essas perguntas, nossas abordagens sobre a compreensão do que é escrever e a significação de escritos alheios vão se limitar a questões de código (ortografia, vocabulário, gramática, sintaxe e estilo) e significações descontextualizadas (supondo que tais coisas possam, de fato, existir). As respostas a essas perguntas nos darão a base sobre a 
qual desenvolver uma retórica da língua escrita. (BAZERMAN, 2015, p. 21).

A escrita na escola como foco na língua é relativamente uma prática normativa e gramatiqueira, que implica atenção aos erros de pontuação, regência, concordância, pronomilizações, classe de palavras em geral e sintaxe, negligenciando o processo de criação, de escolhas lexicais, que privilegiem a adesão daquele que lê e a interação escritor-leitor.

Ao adotar esse procedimento, evidentemente, a norma, o contexto, a interação e o sujeito-criador perdem a força, dando lugar à codificação, propriamente dita, de determinado texto.

Sayeg-Siqueira, na década de 1990, já havia entendido o texto como um novo saber, como uma troca de saberes entre escritor-leitor, mesmo ao considerar e reconhecer o fato de que o texto necessita sim de uma unidade, uma introdução, uma organização macro e microestrutural, uma referência e uma tematização. Contudo, nas palavras do autor, o texto emana de uma proposição: "quando iniciamos uma comunicação escrita, temos o propósito de que nossa mensagem atinja o leitor" (SAYEG-SIQUEIRA, 1990, p.28).

E acrescenta:

Sempre quando escrevemos um texto, temos uma certa intenção e só encerramos o texto, colocamos o ponto final, quando sentimos que essa intenção está cumprida, ou seja, dissemos tudo que queríamos dizer. Para um texto ser um texto, não basta simplesmente ter uma referência e uma tematização, ele precisa trazer uma informação nova, isto é, algo que o autor considere como não sendo do conhecimento de todos, não sendo, portanto, do saber partilhado. Imagine se fossemos escrever um texto sobre a guerra e começássemos assim: Guerra é sempre uma coisa terrível. Certamente o leitor acharia inútil, pois o texto não traz nenhuma informação nova. Sendo assim, por que esse texto foi escrito? Para que lê-lo? Sempre que se escreve um texto é porque se tem algo de novo a dizer. Sempre que se lê um texto é porque se busca uma informação nova sobre o assunto (SAYEG-SIQUEIRA, 1990, p. 28-29).

É nesse sentido que pensar uma retórica da escrita é fundamental. "A retórica é a arte reflexiva do enunciado estratégico em contexto do ponto de vista dos participantes, tanto falantes quanto ouvintes, escritores e leitores" (BAZERMAN, 2015, p. 21). "Escrever um texto não é simplesmente lançar no papel uma série de palavras, de frases”, contribui Sayeg-Siqueira (1990, 
p. 21). Para Bazerman (2015), "a retórica ajuda-nos a pensar em maneiras como poderíamos usar mais eficazmente palavras para alcançar nossos fins no intercâmbio social" (BAZERMAN, 2015, p. 21-22) e entendemos a escrita, efetivamente, como uma prática de ação, de interação, intrinsecamente social.

\section{Invenção}

As quatro partes da retórica ou etapas do processo persuasivo, como mencionam Figueiredo, Magalhães e Rodrigues-Alves (2016), são: invenção, elocução, disposição e ação. Para este capítulo daremos enfoque na primeira delas.

A invenção tem relação direta com o orador. Mas quem é o orador? É aquele que escreve o discurso? Não necessariamente! Contudo, aquele que escreve o discurso e o sujeito que o transmite podem ser a mesma pessoa. Se o orador pode ser aquele que escreve e enuncia o próprio discurso - como no caso da autobiografia -, pressupõe-se, neste caso, essa relação intrínseca entre orador, invenção e autoria.

Ao considerar que nosso olhar está voltado para o autor, que também é orador, interessa-nos, a partir desses dois primeiros ensinamentos, apresentar mais detidamente a primeira etapa do processo persuasivo.

A invenção tem origem no verbo "invenire", cujo significado para a Retórica é o de achar, encontrar, não no sentido de buscar algo novo, mas o que já existe, entretanto, não basta apenas descobrir os argumentos, é preciso julgar se são adequados para o fim que se pretende com o discurso (TRINGALI, 2014). Refere-se ao estoque de material de onde se extraem os argumentos, afirma Mosca (2004). Ferreira (2010) completa ao dizer que "é também nesse momento que se interroga sobre o auditório, identifica-se com ele para que possa estabelecer acordos, encurtar distâncias por meio do assunto que irá desenvolver" (FERREIRA, 2010, p. 63).

Com base nas citações, percebemos que há, de certa forma, um momento de autoria; trata-se da busca por provas que sustentarão o ambiente discursivo. É no momento da invenção que o orador mostra seu conhecimento sobre o assunto e se faz parecer sincero para ganhar a confiança do auditório, do público-alvo, do leitor. Falamos aqui das três provas retóricas que colaboram para o processo persuasivo: ethos, pathos e logos. A primeira reside no caráter do orador; a segunda refere-se às paixões e emoções 
suscitadas no auditório; e a terceira está centrada no próprio discurso.

Para reconhecer esse orador, toda informação é válida, "informações que ajudem a entender o contexto o autor e suas posições” (FERREIRA, 2010 , p.52). Portanto, algumas perguntas são feitas para o texto, a fim de buscar uma aproximação com o orador: Quem fala? A quem fala? Quando fala? Por que fala? Contra o quê? Como fala?.

Fiorin (2015) colabora ao afirmar que no estoque de material, denominado por ele como inventário, encontram-se os lugares (topói), objeto de estudo dos autores da Nova Retórica, Perelman \& Tyteca (2014), quando escreveram o Tratado da Argumentação. Esses autores os definem como depósito de argumentos e mencionam que Aristóteles distinguia os lugarescomuns (utilizados por qualquer campo discursivo) dos lugares específicos (usados em um gênero oratório bem definido).

Apresentamos no Quadro 1, com base nos ensinamentos de Ferreira (2010, p. 70-76), as definições sintetizadas dos lugares-comuns da quantidade, da qualidade, da ordem, do existente, da essência e da pessoa.

Quadro 1: Lugares-comuns

\begin{tabular}{|l|l|}
\hline Lugares & Descrição \\
\hline $\begin{array}{l}\text { Da } \\
\text { quantidade }\end{array}$ & $\begin{array}{l}\text { é o que afirma que uma coisa é preferível a outra em razão } \\
\text { de dados quantitativos, que uma coisa é superior à outra por } \\
\text { ser mais proveitosa a um número maior de pessoas, ser mais } \\
\text { durável, mais útil. É um lugar que fundamenta anúncios } \\
\text { publicitários. }\end{array}$ \\
\hline Da qualidade & $\begin{array}{l}\text { é preferível aquilo que se sobrepõe ao outro por ser } \\
\text { raro, original, extraordinário. A opinião de determinado } \\
\text { indivíduo é melhor que a de todos. Trata-se de um } \\
\text { argumento elitista }\end{array}$ \\
\hline Da ordem & $\begin{array}{l}\text { afirma a superioridade da causa sobre o efeito, do anterior } \\
\text { sobre o posterior. Glorifica-se o passado e menospreza-se } \\
\text { o presente. Também pertence a esse lugar o argumento } \\
\text { contrário. }\end{array}$ \\
\hline Do existente & $\begin{array}{l}\text { declara superioridade daquilo que é sobre aquilo que } \\
\text { somente é possível, do prático sobre o teórico }\end{array}$ \\
\hline Da essência & $\begin{array}{l}\text { contempla os argumentos que mostram indivíduos que } \\
\text { representam um padrão, uma essência }\end{array}$ \\
\hline Da pessoa & $\begin{array}{l}\text { apela ao valor da pessoa, pelo seu valor, sua importância; } \\
\text { valoriza o que é feito com cuidado, carinho, que requer um } \\
\text { esforço }\end{array}$ \\
\hline
\end{tabular}

Fonte: Os autores (adaptado de Ferreira, 2010, p. 70-76). 
Assim, o autor-orador, ao preparar o seu discurso, aciona o seu inventário e busca nele aqueles argumentos que julga ser mais apropriados à sua intenção argumentativa. Naturalmente que em um discurso podem conter todas as tipologias aqui apresentadas, mas cumpre ao analista retórico identificar quais são as preferências do autor, ou seja, quais lugares-comuns se sobressaem.

\section{Biografia}

Quer a linha biográfica de um indivíduo esteja registrada nas mentes de seus amigos íntimos ou nos arquivos de pessoal de uma organização, e quer ele porte a documentação sobre sua identidade pessoal ou esta documentação esteja armazenada em arquivos, ele é uma entidade sobre a qual se pode estruturar uma história - há um caderno a sua espera pronto para ser preenchido. Ele é, certamente, um objeto para biografia.

Erving Goffman

Biografia é a descrição, apreciação e observação de vida e nossas vidas estão em constante movimento. A partir desse pressuposto, é possível afirmar que não vivemos sem a interferência direta ou indireta de outrem. O outro tem uma influência significativa na vida de cada um de nós. Enxergamonos muito sob a perspectiva do olhar de outrem. Trata-se de como o outro efetivamente nos vê. Nossa história inspira o outro? Somos amados pelas outras pessoas? Odiado por elas?

A biografia é um encontro da identidade com a identificação, portanto, em um cenário biográfico, uma atmosfera biográfica, composta por diários íntimos, diários de viagem, biografias e autobiografias, conversas do cotidiano, revistas de fofoca, tabloides, talk e reality shows etc., centralizado na vida dos outros, "eu", como espectador dessa vida e ser humano, posso "me" identificar tanto com o herói quanto com o vilão.

Nesse sentido, o autor de biografia, aquele que escreverá sobre a vida de outrem, deve olhar o mundo sob a perspectiva deste, olhar o mundo com os olhos do biografado, ter com ele uma relação de parentesco e, por isso, o processo de autoria no gênero biografia se dá pensando, primeiro, em um auditório particular, que é o próprio biografado - quando vivo - e, depois, nos outros, auditório universal, seres humanos como o biografado, 
que trabalham, têm uma religião, uma posição política etc.

Goffman (1982) discorre assertivamente sobre a identidade biográfica e divide a personagem biografada sob duas perspectivas: identidade pessoal e identidade social. A identidade pessoal vai depender do grau de informação que biógrafo-autor poderá colher dessa pessoa, o que pressupõe, no caso da biografia, verdade e veridicção, ou seja, os fatos da vida de determinado indivíduo não podem ser desarticulados e nem contraditórios. "Note-se que essa unicidade inclusiva da linha da vida está em flagrante contraste com a multiplicidade dos 'eus' que se descobrem no indivíduo ao encará-lo sob a perspectiva do papel social", afirma Goffman (1982, p. 73).

Se uma pessoa tem uma história retroativa, um passado negativo, ruim, ou uma história que a desabone, essas informações são características de uma identidade social. Para Bakhtin (2010), o eu-para-si não é um valor biográfico constitutivo da forma e sim tem relação com a identidade pessoal: o que eu sei sobre "mim mesmo" que gostaria de ignorar ou esconder das outras pessoas? "De qualquer forma, a informação prontamente disponível sobre a manipulação da identidade pessoal deve ser buscada nas biografias e autobiografias de pessoas famosas ou de má reputação", assinala Goffman (1982, p.83).

É nas palavras desse mesmo autor que encontramos uma elucidação mais direta para a questão da identidade pessoal e identidade social:

A identidade pessoal, assim como a identidade social, estabelece uma separação, para o indivíduo, no mundo individual das outras pessoas. A divisão ocorre, em primeiro lugar, entre os que conhecem e os que não conhecem. Os que conhecem são aqueles que têm uma identificação pessoal do indivíduo; eles só precisam vê-lo ou ouvir o seu nome para trazer à cena essa informação. Os que não conhecem são aqueles para quem o indivíduo é um perfeito estranho, alguém cuja biografia pessoal não foi iniciada. (GOFFMAN, 1982, p. 77).

A identidade pessoal do indivíduo não é uma particularidade só dele, mas também daqueles que o conhecem, ou seja, é a partir dela que se estabelece também a identidade social.

Acrescenta Goffman (1982), ainda:

Dentro do círculo de pessoas que tem uma informação biográfica sobre alguém - que sabem coisas sobre ele - haverá um círculo menor daqueles que mantêm com ele um vínculo "social", quer 
superficial ou íntimo, e quer como igual ou não. Conforme dissemos, eles não só sabem "de" ou "sobre" ele, como também o conhecem "pessoalmente". Eles terão o direito e a obrigação de trocar um cumprimento, uma saudação e "bater um papo" com ele quando se encontram na mesma situação social, e isto constitui o reconhecimento social. (GOFFMAN, 1982, p. 78).

Quando o biógrafo-autor escreve para aqueles que conhecem o biografado, o faz para um auditório particular, que conhece sua identidade social, mas é, ao buscar a identidade pessoal do biografado, que o biógrafo-autor vai procurar a novidade, o novo, o desconhecido, no intuito de alcançar um auditório mais universal.

Bakhtin (2010, p. 138) afirma "não haver um limite acentuado e de princípio entre biografia e autobiografia" e delineia dois tipos de consciência biográfica: aventuresco-heroica e social de costumes. Para este capítulo, abordaremos o segundo tipo.

No social de costumes, nos é ofertado um viés não histórico, mas essencialmente social. Em um ponto de vista social, a perspectiva de uma verdade pura, inquestionável é ocupada pelos valores sociais e, acima de tudo, familiares. De acordo com Mattos (2015), o sucesso junto aos contemporâneos é o bom homem, honesto e não a glória histórica junto aos descendentes. Trata-se da raça humana e seu cotidiano, na rotina dos heróis vivos. E acrescenta: "Nessa consciência biográfica, não se trata de estar no mundo e ter importância nele, mas de estar com o mundo, observá-lo, vivê-lo e revivê-lo repetidas vezes" (MATTOS, 2015, p. 68).

Nessa consciência biográfica, a fronteira da narração pode invadir a fronteira da personagem biográfica. É verdadeiramente possível, nos gêneros biografia e autobiografia, um intercambiar de posições narrativas.

Leiamos a respeito em Mattos (2015):

Sem me desvincular da vida em que as personagens são os outros e o mundo é o seu ambiente, eu narrador dessa vida me identifico com as personagens dessa vida. É assim que o narrador se torna personagem, caracterizando um primeiro movimento para um processo teoricamente de descuido saudável, frutífero e relevante em que autor, narrador e personagem se confundem, num processo autobiográfico da voz do autor no narrador e, consequentemente, no linear da personagem. É, portanto, de vital importância o conhecimento de parte considerável da biografia por meio das palavras alheias, das pessoas íntimas: a origem, o nascimento, os acontecimentos da vida familiar da personagem; aos quais evidentemente o autor da biografia tem acesso. (MATTOS, 2015, p. 66). 
A importância do outro no gênero biografia justifica o realismo e a simplicidade descritiva da vida. Sempre sob a óptica do outro - que está presente também na relação entre narrador e personagem - seja o narrador começando a narrar sobre o outro que lhe é íntimo, com quem vive uma só vida na família, na nação, na sociedade humana, no mundo, seja o outro a narrar sobre o narrador é um processo possível de escrita essa troca no limiar da personagem entre o narrador-autor e a personagem. Em outras palavras, a narração divide espaço entre a primeira e terceira pessoa entre o gênero biografia e o gênero autobiografia.

\section{O texto biográfico na universidade - apresentação do corpus}

No intento de demonstrar o processo de autoria biográfica no ensino superior, foi selecionado um texto produzido pelo aluno Willian Veríssimo da Cruz sobre a vida de Rodolfo Luiz de Oliveira, ambos concluintes do Curso Superior de Tecnologia em Eventos, de uma faculdade pública, situada na cidade de Cruzeiro, SP, Região Metropolitana do Vale do Paraíba. Os estudantes foram convidados por um de seus professores, autor deste capítulo, para ser o biógrafo e o biografado, respectivamente. A orientação passada foi que Willian considerasse o período em que se conheceram - no caso, há três anos, quando prestaram o vestibular - e pontuasse aspectos sobre a vida, qualidades, preferências, atitudes, comportamentos, principais realizações, enfim, tudo que fosse relevante ser mencionado em uma breve biografia limitada a duas páginas. A produção atingiu o objetivo proposto e o texto gerado por Willian Veríssimo apresentou o resultado de uma biografia propriamente dita, portanto, encontra-se no corpo deste trabalho e será objeto de análise quanto a aspectos relacionados à produção biográfica e aos lugares preferidos do autor. A participação de Rodolfo de Oliveira foi a de ceder a história de sua vida para que seu amigo o biografasse. 


\section{O corpus}

\section{Sonhador}

Meu nome é Willian Veríssimo da Cruz e conheci Rodolfo Luiz de Oliveira, cruzeirense de 39 anos, no primeiro dia em que fui à faculdade por meio de um colega em comum. A partir daí iniciou-se uma amizade, no qual, pretendo levar para a vida toda.

Rodolfo é um sonhador convicto! Ele é o caçula de uma família de 4 filhos. Vive com seu pai, sua mãe, dois irmãos e um sobrinho. Um de seus sonhos lhe fez ir até a cidade de São Paulo para conseguir se tornar um ator com registro profissional e ter o reconhecimento de seus familiares pelo seu esforço e dedicação.

Rodolfo conheceu muitas pessoas boas nesta sua passagem pela megalópole, uma delas é filha do ex-presidente do São Paulo Futebol Clube, que foi uma de suas melhores amizades feita em São Paulo, chamada Claudia. Ela levava Rodolfo pra baixo e pra cima, inclusive para visitar sua mansão em um dos bairros mais ricos da cidade. Em uma dessas visitas ele foi convidado a jantar e encabulado por não saber utilizar-se de tantos talheres, sua amiga Claudia lhe dava dicas preciosas de como se portar à mesa. Ele diz que até se saiu muito bem porque todos o deixavam bem à vontade.

Neste seu período em que viveu na "selva de pedra" ele escrevia em um caderno, que acabou virando um rico diário, digno de roteiro de cinema. Tudo que ele vivia, desde quando acordava até o seu adormecer era catalogado. Ali ele também registrava seus objetivos, suas dúvidas até quando sonhava e ele percebia que naquele contexto poderia sair uma história teatral ou um programa de TV ele lançava em seu diário.

Tive a oportunidade em folhear suas histórias e é de se emocionar, são inúmeros detalhes que, pensando bem, um filme não comportaria tanta riqueza de detalhe.

Rodolfo sofreu sim, mas sua experiência de vida é de se aplaudir de pé, como um espetáculo de Shakespeare, só que da vida real, nua e crua.

Diante de toda a dificuldade ele saiu de tudo isso fortalecido e com a certeza de que seu maior sonho que ele levou de Cru- 
zeiro para ser realizado em São Paulo, irá se concretizar na sua cidade Natal.

Rodolfo trabalhou em uma academia de dublê, participou de pegadinhas no SBT, RecorTV, RedeTV! E nas gincanas também na TV do "Homem do Baú".

Na sua volta a Cruzeiro, ele decidiu voltar a estudar e escolheu o curso técnico em Marketing, no qual, deu base para ele desenvolver um de seus projetos denominado Natal em 3 Atos, em prol do Asilo da cidade.

Terminado seu curso, ele sofreu um forte golpe que foi o falecimento de sua avó, no qual, tinha uma forte ligação.

Passado a dor, ele fez inscrição para o curso Superior em Tecnologia em Evento da Fatec Cruzeiro, no qual, foi muito bem colocado.

Junto com ele, sua sobrinha, Kayane, também prestou concurso para o mesmo curso, orgulhando seu tio porque ele foi fundamental na escolha dela.

Nesses quase 3 anos de amizade, sinto que meu amigo sofreu uma metamorfose pro bem, se tornando muito responsável perante sua Companhia Teatral, em que ele é o fundador, fruto da sua competência a frente dos cursos de verão e inverno que ele realizou na Fatec.

Essa fase em que ele está se tornando um profissional do ramo de eventos teve a oportunidade em participar de um projeto chamado Arte na comunidade em que percorreu, desenvolvendo e passando aos alunos da rede municipal de ensino a história da cidade de Cruzeiro.

Rodolfo está se tornando uma pessoa que está sabendo absorver as dificuldades que a vida oferece, está sabendo passar por cima sem fazer muita força, porém se mostra extremamente sensível quando tocamos em assuntos delicados como: drogas, bebidas e amores.

Hoje, o vejo outra pessoa daquele do primeiro dia de aula, cada vez mais obstinado, focado, profissional, que nunca perdeu sua fé, sempre está de sorriso aberto fazendo suas piadas sem graça, outras vezes com humor negro e outras vezes com a graça que lhe é peculiar.

Meu amigo cresceu e se tornou uma pessoa com asas gigantes para voar e chegar a um patamar nunca antes alcançado. 


\section{Uma breve análise}

Ao pensarmos em um discurso, podemos inferir que o orador do discurso pode não ser necessariamente aquele que o escreveu. No caso da autobiografia, o orador - com raras exceções - é aquele que ora o discurso assentado em um posicionamento enunciativo-discursivo de primeira pessoa do singular.

Observemos no texto do aluno Willian Veríssimo da Cruz que o posicionamento enunciativo discursivo é cambiante, pois muito embora ele escreva sobre Rodolfo Luiz de Oliveira, na maior parte do texto em terceira pessoa, característica do gênero biografia, o autor, em muitos momentos, se coloca como orador desse texto marcado pela primeira pessoa:

Meu nome é Willian Veríssimo da Cruz e conheci Rodolfo Luiz de Oliveira, cruzeirense de 39 anos, no primeiro dia em que fui à faculdade por meio de um colega em comum. A partir daí iniciou-se uma amizade, no qual, pretendo levar para a vida toda.

O orador começa a narrar sobre o outro que lhe é íntimo, com quem vive uma só vida na faculdade, na sociedade, em primeira pessoa. Trata-se de descuido frutífero no limiar do processo de criação, que é a linha tênue que difere biografia de autobiografia. O Exórdio ${ }^{5}$ é em primeira pessoa.

Assim como todo o desenvolvimento, o segundo parágrafo é em terceira pessoa:

Rodolfo é um sonhador convicto! Ele é o segundo filho de mais 3. Vive com seu pai, sua mãe, dois irmãos e um sobrinho. Um de seus sonhos lhe fez ir até a cidade de São Paulo para conseguir se tornar um ator com registro profissional e ter o reconhecimento de seus familiares pelo seu esforço e dedicação.

5 Refere-se à primeira parte de um discurso. Pode ser comparado a uma fala introdutória, inicial. 
Na peroração ${ }^{6}$ o texto volta a ser em primeira pessoa:

Hoje, o vejo outra pessoa daquele do primeiro dia de aula, cada vez mais obstinado, focado, profissional, que nunca perdeu sua fé, sempre está de sorriso aberto fazendo suas piadas sem graça, outras vezes com humor negro e outras vezes com a graça que lhe é peculiar.

Meu amigo cresceu e se tornou uma pessoa com asas gigantes para voar e chegar um patamar nunca antes alcançado.

Observamos aqui esse orador-autor cambiante bem alinhavado na afirmação de Mattos (2015), que reconhece florescer um relaxamento sadio e frutificante dessa relação autor, narrador, personagem, em que as três funções intercambiam posições e se confundem. Trata-se da presença autobiográfica da voz do orador-autor no narrador e da voz do orador-autor na personagem.

Para reconhecer esse orador, toda informação é válida, "informações que ajudem a entender o contexto, o autor e suas posições" (FERREIRA, 2010, p.52). Portanto, algumas perguntas são feitas ao texto, a fim de buscar uma aproximação com o orador e entender o procedimento argumentativo utilizado para encurtar a distância deste orador com seu auditório:

\section{Quem fala?}

Fica claro que o orador é o aluno Willian Veríssimo da Cruz:

Meu nome é Willian Veríssimo da Cruz.

\section{A quem fala?}

O orador escreve para um auditório particular: o seu interlocutor direto, aquele que cede a história, no caso ao aluno Rodolfo Luiz de Oliveira e aos professores que acompanharam a atividade, que, ou seja, os autores deste capítulo. 
Contudo, o orador sabe da publicação do texto e toma alguns cuidados para proteger a face do biografado. Ele olha nesse momento para um auditório universal:

Rodolfo está se tornando uma pessoa que está sabendo absorver as dificuldades que a vida oferece, está sabendo passar por cima sem fazer muita força, porém se mostra extremamente sensível quando tocamos em assuntos delicados como: drogas, bebidas e amores.

O biógrafo e o biografado se omitem. A identidade pessoal do indivíduo não é uma particularidade só dele, mas também daqueles que o conhecem, ou seja, é a partir da identificação pessoal do indivíduo que se estabelece também sua identidade social. Esse cuidado leva o novo, a novidade do texto à condição de coadjuvante. "Sempre que se escreve um texto é porque se tem algo de novo a dizer. Sempre que se lê um texto é porque se busca uma informação nova sobre o assunto" (SAYEG-SIQUEIRA, 1990, p. 28-29).

\section{Por que fala?}

Fala para apresentar o amigo, contar um pouco da história de vida dele, mas também para preservar e enaltecer seu ethos e convencer o auditório de que o biografado é uma pessoa de bem, um batalhador:

Rodolfo trabalhou em uma academia de dublê, participou de pegadinhas no SBT, RecorTV, RedeTV! E nas gincanas também na TV do "Homem do Baú".

$\mathrm{Na}$ sua volta a Cruzeiro, ele decidiu voltar a estudar e escolheu o curso técnico em Marketing, no qual, deu base para ele desenvolver um de seus projetos denominado Natal em 3 Atos, em prol do Asilo da cidade.

Terminado seu curso, ele sofreu um forte golpe que foi o falecimento de sua avó, no qual, tinha uma forte ligação.

Passado a dor, ele fez inscrição para o curso Superior em Tecnologia em Evento da Fatec Cruzeiro, no qual, foi muito bem colocado. 


\section{Fala contra o que?}

Contra a ideia de seu amigo ser visto como um vilão, alguém indesejável, de má reputação.

Se alguém tem um passado negativo, ruim ou uma história que o desqualifique, essas informações são características de uma identidade social. Como afirma Bakhtin (2010), o eu-para-si não é um valor biográfico constitutivo da forma. $\mathrm{O}$ eu-para-si tem relação com a identidade pessoal: O que eu sei sobre "mim" mesmo que gostaria de ignorar ou esconder das outras pessoas?

\section{..., porém se mostra extremamente sensível quando toca- mos em assuntos delicados como: drogas, bebidas e amores.}

\section{Como fala?}

O orador-autor opta por uma escolha lexical que legitime a ideia do biografado ser um vencedor enaltecendo suas qualidades.

Hoje, o vejo outra pessoa daquele do primeiro dia de aula, cada vez mais obstinado, focado, profissional, que nunca perdeu sua fé, sempre está de sorriso aberto...

Trata-se, portanto, de um caminho baseado em dois lugares retóricos: o lugar da qualidade e o lugar derivado do valor de pessoa. O orador-autor faz uma propaganda de seu amigo ao ressaltar suas qualidades e apresenta, de certa forma, o biografado como alguém único, raro:

Meu amigo cresceu e se tornou uma pessoa com asas gigantes para voar e chegar um patamar nunca antes alcançado: lugar da qualidade.

O humano, traço característico do gênero biografia, também é muito ressaltado no texto. Valores como a dignidade, a coragem, a superação, importância da personagem e a valorização do que é feito com cuidado, carinho e que requer um esforço: lugar derivado do valor de pessoa. 


\section{Considerações finais}

A escrita biográfica dos alunos, neste capítulo, aconteceu sob uma perspectiva sóciorretórica, de onde o canal de acesso entre o orador e o auditório está na ação, na interação, na relação biógrafo-biografado, orador-autor e o texto, orador e a busca por argumentos, que apresentassem a personagem biografada e suas qualidades como pessoa. As escolhas lexicais apresentadas levaram aos lugares retóricos da qualidade e do valor de pessoa, que depreendem de uma intenção: convencer o auditório de que o biografado é um sonhador, batalhador, de boa reputação e bem-intencionado. Há uma característica social fundamental: os costumes. "A boa glória junto aos contemporâneos, o homem bom e honesto e não a glória histórica junto aos descendentes" (MATTOS, 2015, p.68) é uma característica visível no texto. Goza de uma alteridade enunciativa entre primeira e terceira pessoas, que contempla a relevância das relações humanas e da máxima bakhtiniana do dialogismo em que "eu" só existe diante de um "você". Este estudo é um caminho ou sugestão na abordagem do gênero biografia e da relação orador-autor que ela implica para o trabalho em sala de aula. 


\section{Referências}

BAKHTIN, M. Estética da criação verbal. Trad. Paulo Bezerra. 5 ed. São Paulo: Martins fontes, 2010.

BAZERMAN, C. Retórica da ação letrada. Trad. Adail Sobral, Angela Dionisio, Judith Chambliss Hoffnagel, Pietra Acunha. São Paulo: Parábola Editorial, 2015.

FERREIRA, L. A. Leitura e persuasão: princípios de análise retórica. São Paulo: Contexto, 2010.

FIGUEIREDO, M. F.; MAGALHÃES, A. L.; RODRIGUES-ALVES, M. S. P.. O ethos de Maria na música popular brasileira. In: MAGALHÃES, A. L.; FERREIRA, L. A.; FIGUEIREDO, M. F. (Orgs.). As mulheres que a gente canta. v. 2. Franca / São Paulo: Cristal / Grupo ERA, 2016. p. 9-36.

FIORIN, J. L. Argumentação. São Paulo: Contexto, 2015.

GOFFMAN, E. Estigma: notas sobre a manipulação da identidade deteriorada Trad. Márcia Bandeira de Mello Leite Nunes. 4 ed. Rio de Janeiro: Zahar Editores, 1982.

KOCH, I. V.; ELIAS, V. M. Ler e Escrever: estratégias de produção textual. 2 ed. São Paulo: Contexto, 2009.

MATTOS, T. R. Biografia e Autobiografia: um estudo do estilo em ambos os gêneros do discurso. São Paulo: Novas Edições Acadêmicas, 2015.

MOSCA, L. Retóricas de ontem e de hoje. São Paulo: Humanitas, 2004.

PERELMAN, C.; OLBRECHTS-TYTECA, L. Tratado da argumentação: a nova retórica. Trad. Maria Ermantina de Almeida Prado Galvão. 3 ed. São Paulo: Editora WMF Martins Fontes, 2014.

SAYEG-SIQUEIRA, J. H. O Texto. São Paulo: Selinunte, 1990.

TRINGALI, D. A retórica antiga e outras retóricas - a retórica como crítica literária. São Paulo: Musa, 2014. 
